\title{
Ulipristal acetate induces cell cycle delay and remodeling of extracellular matrix
}

\author{
SO-JIN SHIN ${ }^{1}$, JINYOUNG KIM ${ }^{2}$, SEUNGMEE LEE ${ }^{1}$, JONGWOO BAEK ${ }^{3}$, \\ JIN EUI LEE ${ }^{4}$, CHIHEUM CHO ${ }^{1}$ and EUNYOUNG HA ${ }^{5}$ \\ ${ }^{1}$ Department of Gynecology and Obstetrics and Institute for Cancer Research; ${ }^{2}$ Department of Internal Medicine, \\ School of Medicine, Keimyung University, Daegu, North Gyeongsang 42403; ${ }^{3}$ Department of Obstetrics and \\ Gynecology, Gumi CHA Hospital, CHA University, Gumi, North Gyeongsang 39295, Republic of Korea; \\ ${ }^{4}$ Department of Biomedical Engineering, Cornell University, Ithaca, NY 14853, USA; ${ }^{5}$ Department of Biochemistry, \\ School of Medicine, Keimyung University, Daegu, North Gyeongsang 42403, Republic of Korea
}

Received January 9, 2018; Accepted July 5, 2018

DOI: $10.3892 /$ ijmm.2018.3779

\begin{abstract}
Uterine leiomyoma is a benign tumor that grows within the muscle tissue of the uterus. Ulipristal acetate (UPA) is a pre-operative drug used to reduce the size of leiomyoma. The aim of the present study was to examine the in vitro mechanistic details of action of UPA on uterine leiomyomas. Primary cultures of leiomyoma cells were isolated from patient myomectomy specimens and incubated in the presence or absence of UPA at various concentrations. The proliferation, cell viability and doubling time properties of the treated cells were analyzed. In addition, the mRNA and protein expression levels of p21, p27, cyclin E, cyclin-dependent kinase 2 (CDK2), matrix metalloproteinase (MMP)-2 and MMP-9 were examined, as well as the structure of F-actin in the primary-cultured leiomyoma cells. The results demonstrated that UPA exerted inhibitory effects on proliferation of primary-cultured leiomyoma cells. Expression of p21 and p27 was upregulated, while cyclin E and CDK2 were downregulated in UPA-treated primary-cultured leiomyoma cells. An increased expression of MMP-2 was observed in primary-cultured leiomyoma cells and a leiomyoma tissue sample of a patient with previous history of UPA treatment. Furthermore, a pronounced formation of F-actin stress fibers was observed in leiomyoma cells
\end{abstract}

Correspondence to: Professor Chiheum Cho, Department of Gynecology and Obstetrics and Institute for Cancer Research, School of Medicine, Keimyung University, 104, Myeongdeok-ro, Daegu, North Gyeongsang 42403, Republic of Korea

E-mail: c0035@dsmc.or.kr

Professor Eunyoung Ha, Department of Biochemistry, School of Medicine, Keimyung University, 104, Myeongdeok-ro, Daegu, North Gyeongsang 42403, Republic of Korea

E-mail: eyha@dsmc.or.kr

Key words: uterine leiomyoma, ulipristal acetate, cell cycle control, extracellular matrix of the UPA-treated patient. These data suggest that UPA treatment attenuated the proliferation of uterine fibroid cells via upregulation of p21 and p27, resulting in cell cycle delay. The findings in the current study also suggest that UPA may cause extracellular matrix constriction, leading to the shrinkage in size of the leiomyoma possibly via stimulation of MMP-2 expression and induction of actin stress fibers.

\section{Introduction}

Uterine leiomyomas, also known as fibroids, are benign hormone-sensitive smooth muscle tumors of the uterus. They contain large amount of extracellular matrix (ECM) and are surrounded by a thin pseudo-capsule of areolar tissues and compressed muscle fibers (1-3). Symptomatic women often suffer from heavy menstrual bleeding, pelvic pressure and pain, thus reducing their quality of life $(4,5)$. A recent study revealed that $53.7 \%$ of women with leiomyomas reported a decline on their life quality with influences in sexual life, performance at work, along with family and daily life (6). The management of symptomatic fibroids has traditionally been through surgical removal via either hysterectomy or myomectomy, and thus far uterine leiomyomas are the most common indication for hysterectomy associated with morbidity and mortality as well as a substantial economic impact on healthcare systems (7). Thus, there is a pressing and urgent need for a more effective, uterus-sparing medical therapy that may improve the fertility outcome of these patients.

Patients with symptomatic leiomyomas often receive hormonal therapies, such as gonadotropin-releasing hormone agonists and selective progesterone receptor modulators, which have been proven to be effective at reducing leiomyoma volume, uterine size, and menstrual blood loss (8). Recently, pre-operative pharmacological treatment of myomas has been approved to control fibroid growth $(9,10)$; Ulipristal acetate (UPA), a selective progesterone receptor modulator (SPRM) that modulates progesterone-receptor activity, is reported to have agonist/antagonist activities depending on the cellular context and has been demonstrated to induce 
apoptosis in cultured leiomyoma cells (11). Evidence suggests that long-term treatment with UPA may control the bleeding and shrinkage on uterine leiomyoma (12).

In vitro studies demonstrate that progesterone stimulates proliferative activity in cultured leiomyoma cells, but not in normal myometrial cells (13). These observations that progesterone has a crucial role in leiomyoma growth triggered studies for hormonal treatments using SPRMs. Altering progesterone receptor signaling, SPRMs can inhibit cellular proliferation of leiomyoma and stimulate the apoptosis of leiomyoma cells. Studies have revealed that asoprisnil, a SPRM, inhibits proliferation, thus stimulating apoptosis, and represses collagen synthesis resulting in the stimulation of ECM resorption (14). A study evaluated the underlying mechanism of UPA and reported that UPA induced the expression of matrix metalloproteinase (MMP)-1 and MMP-8, the proteolytic enzymes involved in tissue remodeling, and decreased the expression of tissue inhibitor of metalloproteinases (TIMP) in cultured leiomyoma cells, but not in cultured myometrial cells (15).

Although the efficacy of UPA on reducing the size of leiomyoma has been firmly established, UPA is only approved for preoperative treatment. UPA is used for temporary treatment prior to surgery in order to manage symptoms of pain, pressure and bleeding, often associated with leiomyomas. Leiomyomas, however, regrow within several months after discontinuation of the UPA treatment, which renders surgery necessary to cure leiomyomas following UPA treatment.

Studies suggest that UPA induces apoptosis thereby decreasing the size of leiomyomas. However, apoptosis alone cannot explain the re-growth of leiomyomas. Thus, the aim of the present study was to investigate the mechanistic details of action of UPA and determine potentially novel mechanisms by which UPA affects leiomyoma growth, with the hope to provide a foundation for novel pharmacological approaches to treat uterine fibroids. As cumulative lifetime risk of leiomyoma is approaching $70 \%$ for women (2), development of novel medical treatments which can cure leiomyomas without surgery has multiple benefit of social and economic aspects.

\section{Materials and methods}

Patient samples. Uterine leiomyoma tissue specimens were collected from patients who underwent myomectomy or hysterectomy at Dongsan Medical center (Daegu, Republic of Korea) between 2010 to 2014. Inclusion criteria were as follows: 20-50 year old women who had been diagnosed by ultrasonography with leiomyoma, and underwent myomectomy or hysterectomy, women who have had medical treatment for leiomyoma were excluded. Uterine leiomyoma tissue specimens collected from women with history of preoperative medical treatment of leiomyoma were used only for the immunohistochemistry assay. Women who met the inclusion criteria were included regardless of history of other diseases. Written informed consent was obtained from all patients and the study was approved by the institutional review board of Dongsan Medical Center (Daegu, Republic of Korea; approval no. 09-156). Leiomyoma specimens from patients with previous history of UPA treatment prior to surgery were compared with those from patients without previous history of UPA treatment prior to surgery, via immunohistochemistry (IHC) analysis.
Specimens from patients without previous history of UPA were also primary-cultured for further study to determine the effects of UPA.

Isolation of uterine leiomyoma cells and culture. Leiomyoma tissues were digested in HBSS medium containing $1.5 \mathrm{mg} / \mathrm{ml}$ collagenase II and $6.5 \mathrm{mg} / \mathrm{ml}$ HEPES (all from Sigma-Aldrich; Merck KGaA, Darmstadt, Germany) for $4 \mathrm{~h}$ in a water bath at $37^{\circ} \mathrm{C}$ and vortexed at an interval of $1 \mathrm{~h}$. Then cells were maintained at $37^{\circ} \mathrm{C}$ in a humidified atmosphere of $5 \% \mathrm{CO}_{2}$ in DMEM/F-12 medium containing 10\% fetal bovine serum and $1 \%$ of antibiotics (all from Gibco; Thermo Fisher Scientific, Inc., Waltham, MA, USA)

Cell viability assay. Cells were seeded in a 48 -well plate for $24 \mathrm{~h}$, and then treated with different concentrations of UPA (Toronto Research Chemicals, Inc., North York, ON, Canada) for $72 \mathrm{~h}$. Cell counting kit-8 (CCK-8) assay was performed to determine cell viability, according to the manufacturer's instructions (Dojindo Molecular Technologies, Inc., Kumamoto, Japan).

Doubling time measurement. Cells were seeded in a 12-well plate, with $2 \times 2 \mathrm{~mm}$ crossing lines drawn at the bottom, at a concentration of 10,000 cells/well with medium containing $10 \%$ fetal bovine serum and $1 \%$ antibiotics. The cells were treated with the indicated concentrations of UPA and the number of cells in each region of the well were counted every 24 h. Doubling time was determined with the following formula: Doubling Time $=\mathrm{TIn} 2 / \operatorname{In}(\mathrm{Xe} / \mathrm{Xb})$; where $\mathrm{T}$ is the incubation time, $\mathrm{Xb}$ is the cell number at the beginning of the incubation time, and $\mathrm{Xe}$ is the cell number at the end of the incubation time.

EdU assay. Cell proliferation was assayed with the Click-iT EdU Imaging kit (Invitrogen; Thermo Fisher Scientific, Inc.). Cells were plated in 8-well chamber slides at a concentration of 10,000 cells/well. Cells were then treated with different concentrations of UPA and incubated for $72 \mathrm{~h}$. Following the $72 \mathrm{~h}$ incubation, cells were labeled with $10 \mu \mathrm{M}$ EdU solution for $24 \mathrm{~h}$ and were photographed for Edu incorporation using a fluorescent microscope, and analyzed using ZEN-2.0 blue edition software (Carl Zeiss, Thornwood, NY, USA).

Western blot immunoassay. Primary-cultured leiomyoma cells were lysed with RIPA buffer (Biosesang Co., Inc., Seongnam, Korea) containing $1 \%$ protease inhibitor (Invitrogen; Thermo Fisher Scientific, Inc.) and $2 \mathrm{mM}$ PMSF. Total protein concentration was determined by Bradford assay. Equal amounts of protein samples [40 $\mu \mathrm{g}$, for MMP-2 and MMP-9 blots; $30 \mu \mathrm{g}$, for $\mathrm{p} 21, \mathrm{p} 27$, cyclin $\mathrm{E}$ and cyclin-dependent kinase 2 (CDK2) blots] were separated by $10 \%$ SDS-PAGE and transferred to nitrocellulose membranes. Membranes were blocked with 5\% skim milk in TBS containing $0.1 \%$ Tween-20 for $1 \mathrm{~h}$. Antibodies against MMP-9 (cat. no. ab38898), MMP-2 (cat. no. ab37150), CDK2 (cat. no. ab32147), cyclin E1 (cat. no. ab3927) were obtained from Abcam (Cambridge, MA, USA), for p21 (cat. no. 2947) and p27 (cat. no. 2552) from Cell Signaling Technology, Inc. (Danvers, MA, USA) and for $\beta$-actin (cat. no. A5316) from Sigma-Aldrich; Merck KGaA. Primary 
antibodies were diluted $(1: 1,000)$ and incubated overnight at $4^{\circ} \mathrm{C}$. Secondary antibodies, goat anti-mouse (cat. no. sc-2005) and goat anti-rabbit (cat. no. sc-2030) with horseradish peroxidase (HRP) conjugate were purchased from Santa Cruz Biotechnology, Inc. (Dallas, TX, USA). Secondary antibodies were diluted $(1: 2,000)$ and incubated at room temperature for $2 \mathrm{~h}$. The blots were developed with enhanced chemiluminescence solution from Pierce (Thermo Fisher Scientific, Inc.) and imaged using a LAS-3000 imager (Fujifilm, Tokyo, Japan). The intensity of each band was normalized against $\beta$-actin and quantified using ImageJ software (National Institutes of Health, Bethesda, MD, USA).

RNA extraction and reverse transcription-quantitative polymerase chain reaction $(R T-q P C R)$ analysis. Total RNA was isolated from leiomyoma cells treated with different concentrations of UPA using acid guanidinium thiocyanate-phenol-chloroform extraction method. Equal amounts of RNA were used for RT-qPCR analysis. Reverse transcription was performed using Reverse Transcriptase (Promega Corporation, Madison, WI, USA), and qPCR analysis was performed using SYBR-Green (Toyobo Co., Ltd., Osaka, Japan). The primer sequences and PCR conditions were as follows; p21, forward, 5'-ATGAAATTCACCCCCTTTCC-3', reverse, 5'-CCCTAGGCTGTGCTCACTTC-3' and annealing temperature and time, $60^{\circ} \mathrm{C}$ for $30 \mathrm{sec}$; p27, forward, 5'-AGA TGTCAAACGTGCGAGTG-3', reverse, 5'-TCTCTGCAG TGCTTCTCCAA-3' and annealing temperature and time, $60^{\circ} \mathrm{C}$ for $30 \mathrm{sec}$; MMP-2, forward, 5'-TATGACAGCTGCACC ACTGA-3', reverse, 5'-TCATCGTAGTTGGCTGTGGT-3' and annealing temperature and time, $60^{\circ} \mathrm{C}$ for $30 \mathrm{sec}$; MMP-9, forward, 5'-GAGTTCGAGTGAGTTGA-3', reverse, 5'-GGC CCTCTCYYCYCACCTTT-3' and annealing temperature and time, $60^{\circ} \mathrm{C}$ for $30 \mathrm{sec}$; GAPDH as an internal control, forward, 5'-TTCGACAGTCAGCCGCATCTTCTT-3', reverse, 5'-GCC CAATACGACCAAATCCGTTGA-3' and annealing temperature and time, $60^{\circ} \mathrm{C}$ for $30 \mathrm{sec}$. The expression was normalized against GAPDH and quantified as previously described (16).

IHC staining. Tissues were fixed with $10 \%$ formalin for $24 \mathrm{~h}$ at room temperature and embedded in paraffin. Formalin-fixed and paraffin-embedded specimens were cut into $4 \mu \mathrm{m}$-thick sections. Tissues were rehydrated using xylene 3 times for $5 \mathrm{~min}$ and a series of graded ethanol (absolute ethanol twice for $5 \mathrm{~min}, 95 \%$ ethanol 2 times for $3 \mathrm{~min}, 80 \%$ ethanol for $3 \mathrm{~min}$ ) at room temperature. Subsequent to being washed with water for $5 \mathrm{~min}$, sections were permeabilized using $3 \%$ $\mathrm{H}_{2} \mathrm{O}_{2}$ in methanol for $15 \mathrm{~min}$ at room temperature, washed again with water for $5 \mathrm{~min}$. For antigen retrieval, sections were immersed in citrate buffer $(150 \mathrm{mM}$ sodium citric- acid, $\mathrm{pH}$ 6.0), boiled for $10 \mathrm{~min}$, cooled to room temperature for $20 \mathrm{~min}$ in ice, washed with water, and blocked with $2 \%$ goat serum (cat. no. 16210072; Gibco; Thermo Fisher Scientific, Inc.) in PBS for $30 \mathrm{~min}$ at room temperature. The tissues were incubated with anti-MMP-9 (1:500; cat. no. ab38898; Abcam, Cambridge, UK) and anti-MMP-2 (1:200; cat. no. ab37150; Abcam) antibodies overnight at $4^{\circ} \mathrm{C}$. The sections were then washed with PBS prior to incubation with horseradish peroxidase-conjugated goat anti-rabbit antibody $(1: 1,000$; cat. no. SC-2004; Santa Cruz Biotechnology, Inc.) in 1\% goat serum at room temperature for $1 \mathrm{~h}$. Sections were then washed with PBS for $10 \mathrm{~min}$, visualized using a mixture of diaminobenzidine chromogen (cat. no. SK-4105; Vector Laboratories, Burlingame, CA, USA) and analyzed under a light microscope (magnification, x200; Nikon Corporation, Tokyo, Japan).

Actin stress fiber staining. Primary-cultured leiomyoma cells were seeded in 8 -well chambers. Following $24 \mathrm{~h}$ incubation, cells were treated with different concentrations of UPA in serum-free media and incubated for an additional $72 \mathrm{~h}$. Cells were then exposed to media with $10 \%$ fetal bovine serum for $6 \mathrm{~h}$ to stimulate the cell cycle. Actin stress fiber staining was performed with the F-Actin Visualization Biochem Kit (Cytoskeleton, Inc., Denver, CO, USA). Cells were fixed for $20 \mathrm{~min}$ and permeabilized for $15 \mathrm{~min}$ at room temperature. The chamber slide was then incubated in the dark with $100 \mathrm{nM}$ rhodamine phalloidin (Cytoskeleton, Inc.) at room temperature for $30 \mathrm{~min}$. Nuclei were counterstained with 100 nM DAPI (Invitrogen; Thermo Fisher Scientific, Inc.). Glass slides were sealed with mounting solution and analyzed by epifluorescence microscopy.

Statistical analysis. Each experiment was repeated at least three times. All data were calculated as relative values and presented as means \pm standard deviation. Statistical analyses were performed with one-way analysis of variance followed by Tukey's post-hoc test. $\mathrm{P}<0.05$ was considered to indicate a statistically significant difference. The SAS statistical software package (version 8.02; SAS Institute Inc., Cary, NC, USA) was used for analysis.

\section{Results}

UPA inhibits proliferation of primary-cultured leiomyoma cells. CCK-8 assay was performed to determine the effect of UPA on the viability of uterine leiomyoma cells that had been treated with different concentrations of UPA for $72 \mathrm{~h}$. Leiomyoma cells exposed to 1 and $10 \mu \mathrm{M}$ of UPA exhibited decreased viability compared with control cells, in a dose-dependent manner (Fig. 1A). Next, the doubling-time of primary-cultured leiomyoma cells was measured to investigate the possibility of UPA exerting regulatory action on the proliferation of leiomyoma cells. As illustrated in Fig. 1B, a decreased number of cells was observed with increasing time lapse in UPA-treated cells compared with control cells. The doubling time of control leiomyoma cells was $\sim 2$ days (2.0 \pm 0.18 days), while the doubling time of UPA-treated leiomyoma cells was $\sim 3.6$ days (UPA $1 \mu \mathrm{M}, 3.0 \pm 0.5$ days; UPA $10 \mu \mathrm{M}, 3.4 \pm 0.9$ days; Fig. 1B). These results clearly indicate that UPA had an anti-proliferation effect on leiomyoma cells.

To validate the inhibitory effect of UPA on the proliferation of leiomyoma cells, an EdU incorporation assay was performed. The results demonstrated that the proliferation rate of UPA-treated leiomyoma cells decreased to $\sim 50 \%$ relative to the control cells (UPA $1 \mu \mathrm{M}, 6 \pm 10.1 \%$ of control; UPA $10 \mu \mathrm{M}$, $51 \pm 15.0 \%$ of control; Fig. 1C).

UPA induces cell cycle delay via upregulation of $p 21$ and p27. To further determine the mechanistic details of the anti-proliferation 

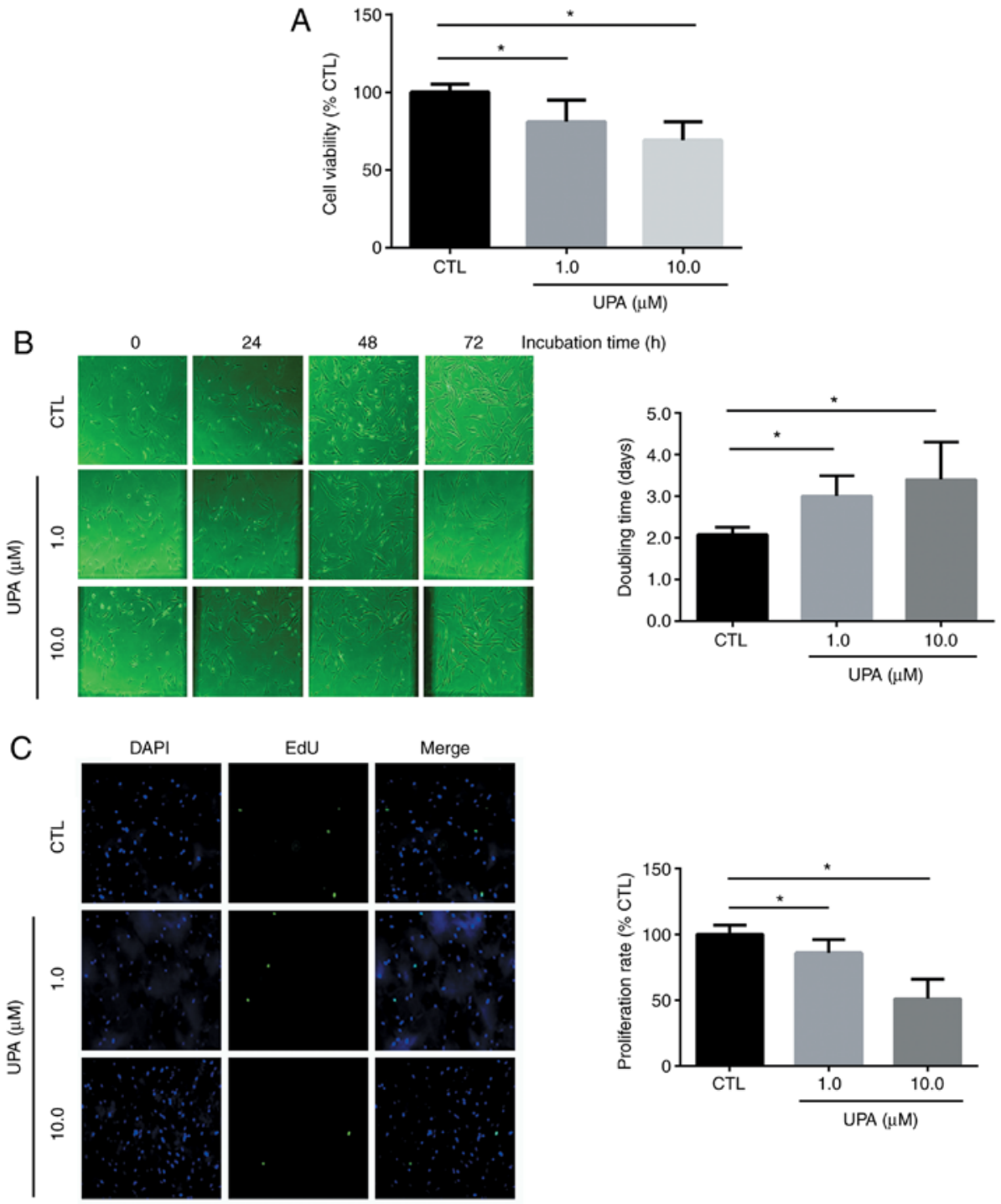

Figure 1. UPA treatment inhibits proliferation in primary-cultured leiomyoma cells. (A) The effect of UPA on the viability of uterine leiomyoma cells was determined by cell counting kit- 8 assay. (B) Representative images of primary-cultured leiomyoma cells treated with UPA for the indicated times, and quantification of their doubling-time. (C) Representative images and quantification of EdU incorporation assay in leiomyoma cells treated with different concentrations of UPA. Data are presented as mean \pm standard deviation. " $\mathrm{P}<0.05$, with comparisons indicated by lines. UPA, ulipristal acetate; CTL, control.

effect of UPA, the mRNA and protein expression levels of the cell cycle regulatory molecules, p21, p27, cyclin E and CDK2 were evaluated. As presented in Fig. 2A and B, the mRNA expression levels of p21 and p27 were significantly increased in UPA-treated primary-cultured leiomyoma cells compared with control cells. In addition, UPA treatment stimulated the upregulation of p21 and p27 proteins, while it decreased the protein expression of cyclin E and CDK2 (Fig. 2C), which suggests a regulatory role of UPA in leiomyoma cells via cell cycle delay. Fig. 2D presents quantification of the protein expression band intensities derived from three different patients.

UPA upregulates MMP-2 expression. Because of the excessive synthesis of ECM in leiomyoma and of the regulatory role of the ECM on cell proliferation and cell cycle progression (17), the hypothesis that UPA may have a role on ECM remodeling was next examined, by determining the expression levels of MMP-2 and MMP-9. The results demonstrated that the mRNA (Fig. 3A) and the protein (Fig. 3B) expression levels of MMP-2 increased following UPA treatment in a dose-dependent manner. In addition, cytoplasmic and nuclear MMP-2 (brown) staining was markedly increased in the uterine tissue of a patient who had been treated with UPA prior to hysterectomy (Fig. 3C). Furthermore, the protein expression levels of MMP-9 were increased in both UPA-treated primary-cultured leiomyoma cells and in the leiomyoma tissue of a patient who had been treated with UPA prior to hysterectomy (Fig. 3B and C). However, the increase in expression of MMP-9 in UPA-treated leiomyoma tissue was not as extensive as that of MMP-2 (Fig. 3C).

UPA induces stress fiber formation. ECM exerts its effects on cells via relaying signals to adjacent cells to reorganize the assembly of cytoskeletal components. To investigate whether UPA exerted its regulatory effect on cellular cytoskeletal components, primary-cultured leiomyoma cells were immunostained for F-actin stress fibers and analyzed by microscopy. The results revealed pronounced formation of F-actin stress fibers in UPA-treated leiomyoma cells, with distinct lines of 

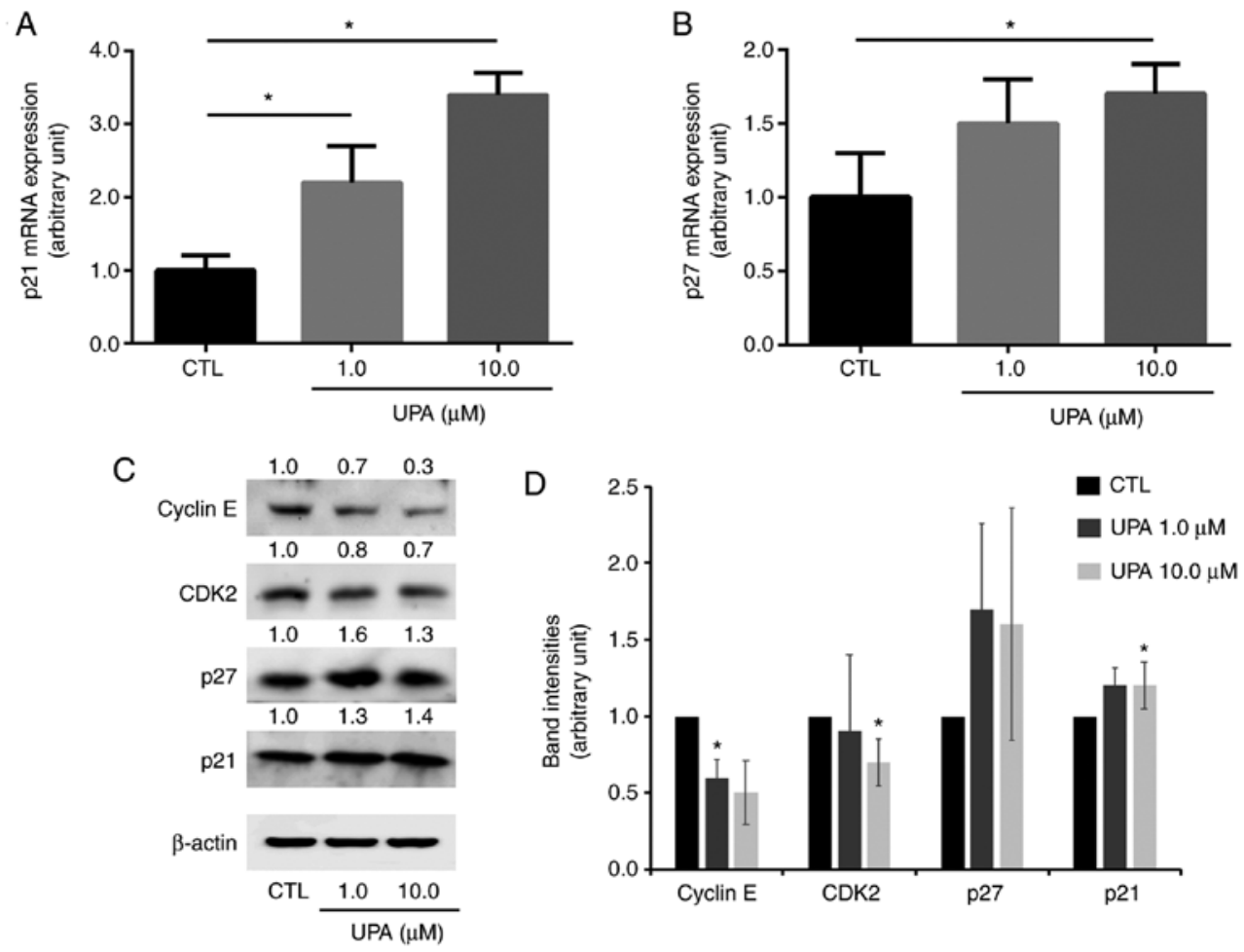

Figure 2. UPA treatment induces cell cycle delay via upregulation of p21 and p27. (A) mRNA expression of p21 in UPA-treated primary-cultured leiomyoma cells. (B) mRNA expression of p27 in UPA-treated primary-cultured leiomyoma cells. (C) Representative blot images for protein expression levels of cyclin E, CDK2, p21 and p27 in leiomyoma cells treated with UPA. (D) Quantification of protein expression levels derived from three different patients, and normalized to $\beta$-actin. Data are presented as mean \pm standard deviation (SD). ${ }^{*} \mathrm{P}<0.05$ compared with CTL. UPA, ulipristal acetate; CDK2, cyclin-dependent kinase 2; CTL, control.
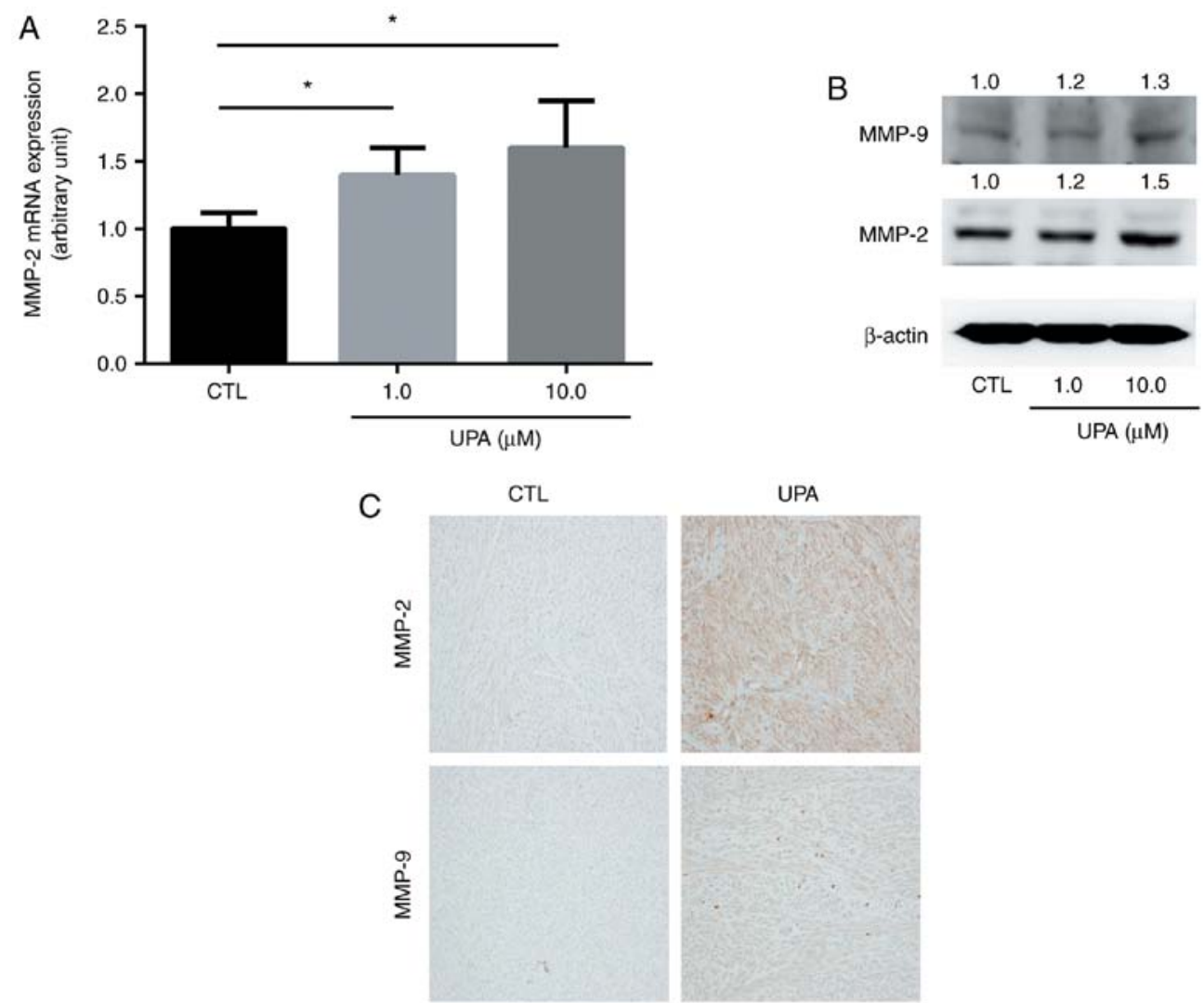

Figure 3. UPA treatment upregulates MMP-2 expression. (A) mRNA expression of MMP-2 in leiomyoma cells treated with UPA. (B) Protein expression levels of MMP-9 and MMP-2 in leiomyoma cells treated with UPA. (C) Representative immunohistochemistry staining of MMP-9 and MMP-2 in uterine samples of patients $(n=4)$ with no UPA treatment (CTL) and with UPA treatment (UPA) prior to hysterectomy $(n=3)$. Data are presented as mean \pm standard deviation. ${ }^{*} \mathrm{P}<0.05$, with comparisons indicated by lines. UPA, ulipristal acetate; MMP, matrix metalloproteinase; CTL, control. 
central and peripheral fibers, compared to the presence of thin, lightly stained peripheral fibers in control cells (Fig. 4).

\section{Discussion}

The present study demonstrated the anti-proliferative action of UPA in primary-cultured leiomyoma cells, which is in accordance with a previous study on other SPRMs (18). In addition, the present results demonstrated the possible underlying mechanistic action of UPA on the proliferation of uterine leiomyoma, via regulation of cell cycle modulators $\mathrm{p} 21$ and $\mathrm{p} 27$ and via modulation of ECM remodeling molecules MMP-2 and MMP-9. Controlled proliferation and differentiation of uterine leiomyoma cells are crucial in the development of leiomyoma (19). Cyclin E/CDK2 complexes are responsible for the transition of the cells cycle from the G1 to the S phase (20). p27 is an inhibitor of CDK2 that controls progression through the G1 phase (21). A previous study has reported that induction of the CDK inhibitor p21 results in the growth inhibition of leiomyoma cells (22). A previous study from our group has also previously demonstrated that expression of p27 increased in leiomyoma cells and overexpression of p27 stimulated apoptosis thus attenuating proliferation of leiomyoma cells (19).

The present data demonstrated that UPA treatment upregulated the expression of p21 and p27, while it downregulated the expression of cyclin $\mathrm{E}$ and CDK2 in primary-cultured uterine leiomyoma cells. These findings suggest that UPA may induce cell cycle arrest in the G1 phase, leading to suppression of cell proliferation, through interrupting the transition from G1 to $S$ phase.

One of the prominent features of uterine leiomyoma is the excessive deposition of ECM proteins $(2,3)$. ECM exerts important roles beyond providing a structural scaffold in tissues. ECM has pivotal roles in cell proliferation, differentiation, adhesion, and apoptosis via relaying signals to adjacent cells (23). Evidence suggests that the morphologies as well as proliferation of leiomyoma cells varied according to different collagen scaffolds, implicating involvement of ECM in the pathophysiology of leiomyoma (17). Studies have also demonstrated that ECM remodeling in leiomyomas is proportional to the expression levels of MMPs $(24,25)$. MMPs are abundantly present in both myometrium and leiomyoma, of which MMP-2 is the most abundant and implicated for remodeling of ECM in the growing leiomyoma (26). The present study revealed that the expression of MMP-2 was increased in UPA-treated primary-cultured leiomyoma cells and in a tissue sample of a patient with previous history of UPA treatment. This result is in agreement with a previous study reporting that a SPRM, asoprisnil, decreases collagen synthesis in uterine leiomyoma cells by upregulating MMP-1 (13). However, the result in the present study is different from that previous study, in that the upregulated MMP by UPA is MMP-2, which is most abundant in leiomyoma. This result might explain the high efficacy of UPA in treating leiomyomas compared with that of other SPRM.

Actin is a major component of the cytoskeleton that regulates various cellular processes such as migration, morphogenesis, cytokinesis, endocytosis and phagocytosis $(27,28)$. Changes in the organization of the cytoskeleton are attributable to

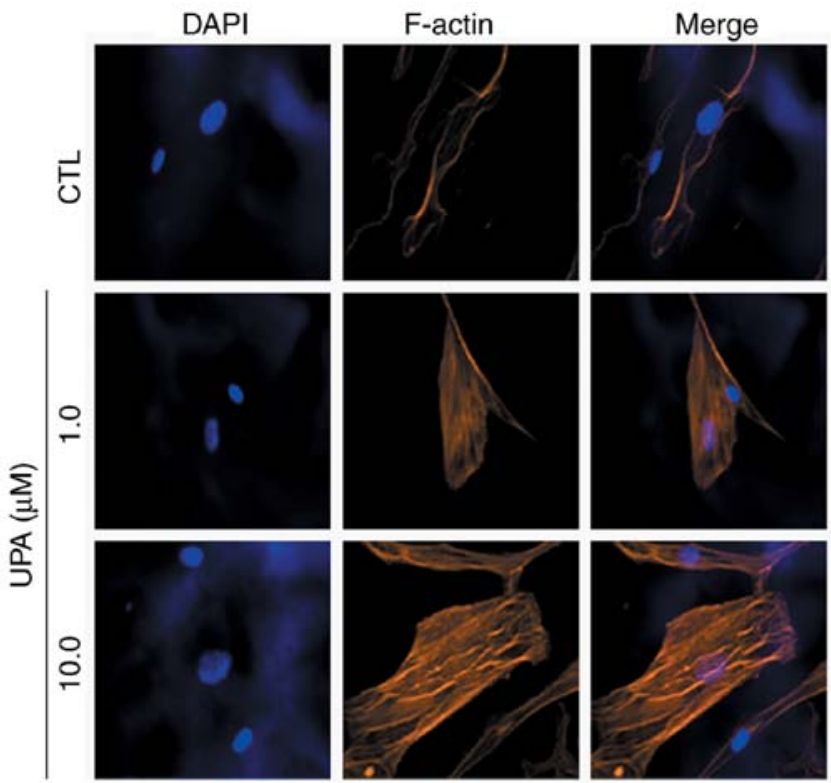

Figure 4. UPA treatment induces stress fiber formation. Representative images from immunostaining of primary-cultured leiomyoma cells for F-actin stress fibers. F-actin fibers are presented in red in the images, while DAPI-stained nuclei are presented in blue. UPA, ulipristal acetate; CTL, control.

cellular morphogenesis, as well as transformation and apoptosis $(29,30)$. Formation of actin stress fiber may both inhibit and stimulate apoptosis depending on upstream signals $(31,32)$. A previous study presented that retinoic acid responsive thymosin $\beta-10$ accelerates apoptosis by disrupting stress fiber formation in fibroblasts (31). Another study reported that tumor necrosis factor- $\alpha$ stimulates apoptosis via myosin light chain phosphorylation-mediated induction of actin stress fiber formation in endothelial cells (32). The results in the current study revealed an increased formation of stress fibers in UPA-treated leiomyoma cells compared with control cells. Although this result is likely to suggest a pro-apoptotic role of stress fibers in UPA-treated leiomyoma cells, further studies to determine the upstream signals and the associated regulatory mechanisms are required to validate the role of UPA in leiomyoma and to exploit the possible connection between formation of stress fibers and ECM constriction.

UPA, originally developed as a synthetic derivative of steroid 19-norprogesterone and approved in Europe for preoperative fibroid treatment, acts on the progesterone receptors in progesterone-responsive tissues $(33,34)$. Phase III clinical trials have demonstrated the safety and efficacy of intermittent treatment of UPA on shrinkage of uterine fibroids $(1,18,35)$ and another study also revealed that UPA had sustained effect on size reduction of leiomyomas for 6 months (36). However, evidence that supports UPA as curative medical treatment without surgery is lacking. In clinical settings, UPA treatment alone cannot provide long-term sustainable therapeutic effect on size reduction, nor complete removal of uterine fibroids. Thus, there remains a substantial unmet need for the development of more effective medical therapies.

The present study has several limitations. First, due to the limited number of primary-cultured leiomyomas, inter-individual variabilities in the response to UPA treatment have not been determined to the extent of statistical 
significance. Second, since leiomyoma is a benign tumor that grows very slowly and cannot be cultured beyond passage two, RT-qPCR, western blotting and IHC data were obtained from different patients, thereby resulting in inter-individual variability. Lastly, the current results were obtained from in vitro experiments, and need to be validated in vivo. Nonetheless, the present study suggests that the UPA therapeutic effect may occur via ECM remodeling. These findings provide the mechanistic foundations based on which more effective therapeutic treatments, such as targeting ECM remodeling, could be developed in the future.

\section{Acknowledgements}

Not applicable.

\section{Funding}

This study was supported by a Scholar Research Grant of Keimyung University in 2015 , by a research promoting grant from the Keimyung University Dongsan Medical Center in 2012 and by the Basic Science Research Program through the National Research Foundation of Korea funded by the Ministry of Science and Information and Communications Technology (grant no. NRF-2015R1A2A2A01007167 to C.H. Cho).

\section{Availability of data and materials}

The analyzed datasets generated during the study are available from the corresponding author on reasonable request.

\section{Authors' contributions}

SS and JK designed and directed the project. SS, JK, JB and JL performed the experiments. SL and CC contributed to the acquisition of data. SS, JK, SL, CC and EH contributed to the interpretation of the results. SS wrote the manuscript with support from SL and EH. CC and EH supervised the project. All authors discussed the results and commented on the manuscript.

\section{Ethics approval and consent to participate}

Written informed consent was obtained from all patients and the study was approved by the institutional review board of Dongsan Medical Center (approval no. 09-156).

\section{Patient consent for publication}

Not applicable.

\section{Competing interests}

The authors declare that they have no competing interests.

\section{References}

1. Malik M, Norian J, McCarthy-Keith D, Britten $\mathrm{J}$ and Catherino WH: Why leiomyomas are called fibroids: The central role of extracellular matrix in symptomatic women. Semin Reprod Med 28: 169-179, 2010.
2. Leppert PC, Baginski T, Prupas C, Catherino WH, Pletcher S and Segars JH: Comparative ultrastructure of collagen fibrils in uterine leiomyomas and normal myometrium. Fertil Steril 82 (Suppl 3): 1182-1187, 2004.

3. Stewart EA: Uterine fibroids. Lancet 357: 293-298, 2001.

4. Buttram VC Jr and Reiter RC: Uterine leiomyomata: Etiology, symptomatology, and management. Fertil Steril 36: 433-445, 1981.

5. Flake GP, Andersen J and Dixon D: Etiology and pathogenesis of uterine leiomyomas: A review. Environ Health Perspect 111: 1037-1054, 2003

6. Zimmermann A, Bernuit D, Gerlinger C, Schaefers $M$ and Geppert K: Prevalence, symptoms and management of uterine fibroids: An international internet-based survey of 21,746 women. BMC Womens Health 12: 6, 2012.

7. Flynn M, Jamison M, Datta S and Myers E: Health care resource use for uterine fibroid tumors in the United States. Am J Obstet Gynecol 195: 955-964, 2006.

8. Kashani BN, Centini G, Morelli SS, Weiss G and Petraglia F: Role of medical management for uterine leiomyomas. Best Pract Res Clin Obstet Gynaecol 34: 85-103, 2016.

9. Bendifallah S, Brun JL and Fernandez H: Myomectomy for infertile women: The role of surgery. J Gynecol Obstet Biol Reprod (Paris) 40: 885-901, 2011 (In French).

10. Yun BS, Seong SJ, Cha DH, Kim JY, Kim ML, Shim JY and Park JE: Changes in proliferating and apoptotic markers of leiomyoma following treatment with a selective progesterone receptor modulator or gonadotropin-releasing hormone agonist. Eur J Obstet Gynecol Reprod Biol 191: 62-67, 2015.

11. Horak P, Mara M, Dundr P, Kubinova K, Kuzel D, Hudecek R and Chmel R: Effect of a selective progesterone receptor modulator on induction of apoptosis in uterine fibroids in vivo. Int $\mathrm{J}$ Endocrinol 2012: 436174, 2012.

12. Maruo T, Ohara N, Matsuo H, Xu Q, Chen W, Sitruk-Ware R and Johansson ED: Effects of levonorgestrel-releasing IUS and progesterone receptor modulator PRM CDB-2914 on uterine leiomyomas. Contraception 75 (Suppl 6): S99-S103, 2007.

13. Morikawa A, Ohara N, Xu Q, Nakabayashi K, DeManno DA, Chwalisz K, Yoshida S and Maruo T: Selective progesterone receptor modulator asoprisnil down-regulates collagen synthesis in cultured human uterine leiomyoma cells through up-regulating extracellular matrix metalloproteinase inducer. Hum Reprod 23: 944-951, 2008.

14. Cawston TE and Young DA: Proteinases involved in matrix turnover during cartilage and bone breakdown. Cell Tissue Res 339: 221-235, 2010.

15. Islam MS, Protic O, Giannubilo SR, Toti P, Tranquilli AL, Petraglia F, Castellucci M and Ciarmela P: Uterine leiomyoma: Available medical treatments and new possible therapeutic options. J Clin Endocrinol Metab 98: 921-934, 2013.

16. Vandesompele J, De Preter K, Pattyn F, Poppe B, Van Roy N, De Paepe A and Speleman F: Accurate normalisation of real-time quantitative RT-PCR data by geometric averaging of multiple internal control genes. Genome Biol 3: RESEARCH0034, 2002.

17. Koohestani F, Braundmeier AG, Mahdian A, Seo J, Bi J and Nowak RA: Extracellular matrix collagen alters cell proliferation and cell cycle progression of human uterine leiomyoma smooth muscle cells. PloS One 8: e75844, 2013.

18. Donnez J, Vazquez F, Tomaszewski J, Nouri K, Bouchard P, Fauser BC, Barlow DH, Palacios S, Donnez O, Bestel E, et al: Long-term treatment of uterine fibroids with ulipristal acetate. Fertil Steril 101: 1565-1573 e1561-1518, 2014.

19. Ramachandran S, Kwon KY, Shin SJ, Kwon SH, Cha SD, Bae I and Cho CH: Cyclin-dependent kinase inhibitor p27 ${ }^{\mathrm{Kipl}}$ controls growth and cell cycle progression in human uterine leiomyoma. J Korean Med Sci 23: 667-673, 2008.

20. Koff A, Giordano A, Desai D, Yamashita K, Harper JW, Elledge S, Nishimoto T, Morgan DO, Franza BR and Roberts JM: Formation and activation of a cyclin E-cdk 2 complex during the G1 phase of the human cell cycle. Science 257: 1689-1694, 1992.

21. Slingerland J and Pagano M: Regulation of the cdk inhibitor $\mathrm{p} 27$ and its deregulation in cancer. J Cell Physiol 183: 10-17, 2000.

22. Shime H, Kariya M, Orii A, Momma C, Kanamori T, Fukuhara K, Kusakari T, Tsuruta Y, Takakura K, Nikaido T and Fujii S: Tranilast inhibits the proliferation of uterine leiomyoma cells in vitro through G1 arrest associated with the induction of p21(waf1) and p53. J Clin Endocrinol Metab 87: 5610-5617, 2002.

23. Flake GP, Moore AB, Flagler N, Wicker B, Clayton N, Kissling GE, Robboy SJ and Dixon D: The natural history of uterine leiomyomas: Morphometric concordance with concepts of interstitial ischemia and inanosis. Obstet Gynecol Int 2013: 285103, 2013. 
24. Palmer SS, Haynes-Johnson D, Diehl T and Nowak RA: Increased expression of stromelysin $3 \mathrm{mRNA}$ in leiomyomas (uterine fibroids) compared with myometrium. J Soc Gynecol Investig 5: 203-209, 1998.

25. Dimitrova IK, Richer JK, Rudolph MC, Spoelstra NS, Reno EM, Medina TM and Bradford AP: Gene expression profiling of multiple leiomyomata uteri and matched normal tissue from a single patient. Fertil Steril 91: 2650-2663, 2009.

26. Wolańska M, Sobolewski K, Bańkowski E and Jaworski S: Matrix metalloproteinases of human leiomyoma in various stages of tumor growth. Gynecol Obstet Invest 58: 14-18, 2004.

27. Pollard TD and Cooper JA: Actin and actin-binding proteins A critical evaluation of mechanisms and functions. Annu Rev Biochem 55: 987-1035, 1986.

28. Tojkander S, Gateva G and Lappalainen P: Actin stress fibers-assembly, dynamics and biological roles. J Cell Sci 125: $1855-1864,2012$.

29. Desouza M, Gunning PW and Stehn JR: The actin cytoskeleton as a sensor and mediator of apoptosis. Bioarchitecture 2: 75-87, 2012.

30. Franklin-Tong VE and Gourlay CW: A role for actin in regulating apoptosis/programmed cell death: Evidence spanning yeast, plants and animals. Biochem J 413: 389-404, 2008.

31. Hall AK: Thymosin beta-10 accelerates apoptosis. Cell Mol Biol Res 41: 167-180, 1995.

32. Petrache I, Verin AD, Crow MT, Birukova A, Liu F and Garcia JG: Differential effect of MLC kinase in TNF-alpha-induced endothelial cell apoptosis and barrier dysfunction. Am J Physiol Lung Cell Mol Physiol 280: L1168-L1178, 2001.
33. Blithe DL, Nieman LK, Blye RP, Stratton P and Passaro M: Development of the selective progesterone receptor modulator CDB-2914 for clinical indications. Steroids 68: 1013-1017, 2003.

34. Busfield RA, Farquhar CM, Sowter MC, Lethaby A, Sprecher M Yu Y, Sadler LC, Brown P and Johnson N: A randomised trial comparing the levonorgestrel intrauterine system and thermal balloon ablation for heavy menstrual bleeding. BJOG 113: 257-263, 2006

35. Donnez J, Donnez O, Matule D, Ahrendt HJ, Hudecek R, Zatik J, Kasilovskiene Z, Dumitrascu MC, Fernandez H, Barlow DH, et al: Long-term medical management of uterine fibroids with ulipristal acetate. Fertil Steril 105: 165-173 e164, 2016.

36. Donnez J, Tomaszewski J, Vázquez F, Bouchard P, Lemieszczuk B, Baró F, Nouri K, Selvaggi L, Sodowski K, Bestel E, et al: Ulipristal acetate versus leuprolide acetate for uterine fibroids. N Engl J Med 366: 421-432, 2012.

This work is licensed under a Creative Commons Attribution-NonCommercial-NoDerivatives 4.0 International (CC BY-NC-ND 4.0) License. 